\title{
Development of shirt pattern for wheelchair tennis players through 3D avatars
}

\begin{abstract}
This study is to develop the wheelchair tennis pattern to improve comfort by reducing garment strain in a CAD program by analyzing seven body movements related to garment strain during play. The bodice was subdivided into surface zones in the present study to efficiently develop 2D patterns that can later be transferred into 3D virtual garments and draped onto $3 \mathrm{D}$ avatars. The $2 \mathrm{D}$ patterns were developed based on morphological analysis that provided different possible solutions to enhance comfort by releasing garment strain at each surface zone. The structural lines and wearing ease grade points were utilized to adjust a tennis shirt block pattern when developing this 2D pattern at morphological analysis step. In this study, 3D body scanner was used to create 3D avatars with postures based on the determined seven body movements. The drafted pattern was used to drape the virtual garments on the each movement of 3D avatars in the CAD program, and then the stain areas of the pattern design were identified using the tension map. In all of the movements, the majority of garment strain appeared on the shoulder surface and around the neck within the surface zone of bodice shoulder angle. The majority of other strain found was on the shoulder blade as the bodice bust zone during movements in the forehand swing, backhand swing, serve toss, and serve follow through postures. Based on these strain results obtained from 3D scanner, the first pattern was developed to release strains in shoulder as seen by the significant decrease in strain during both forehand movements. The second pattern was constructed to release other maximized strain on the back surface zone of the shoulder blade. Based on the results of this study, it should be noted that the shoulder and the shoulder blade areas are important during development of patterns in terms of decreasing strain for comfort during wheelchair tennis play movements.
\end{abstract}

Keywords: comfort, 3D avatars, wheelchair tennis players, strain, morphological analysis
Volume 6 Issue 2 - 2020

\section{Hee Jae Jin, Kathy Mullet}

Department of Design and Human Environment, Oregon State University, USA

Correspondence: Hee Jae Jin, Kongju National University Industry-University Cooperation Foundation, 56, Gongjudaehakro, Gongju-si, Chungcheongnam-do, Republic of Korea, Tel 82-4I-850-050I, Fax 82-4I-856-050I,

Email heejaejin@gmail.com

Received: April 20, 2020 | Published: April 27, 2020

\section{Introduction}

Many researchers have studied the relationships between physical fitness and health for individuals with disabilitiesto improve the quality of life for individuals with disabilities. Individuals with spinal cord injuries are more prone to develop cardiovascular diseases due to limitation of their physicalities that lead to a sedentary lifestyle. ${ }^{1}$ To overcome these health risks, wheelchair tennis has become a popular mode of rehabilitation over the past ten years. ${ }^{2}$

Even though there has been research of wheelchair tennis that considers environmental conditions and athletes with disabilities with the goal of improving mobility and performance, ${ }^{3,4}$ research on the clothing for wheelchair tennis players, particularly on satisfaction of clothing for tennis play, has been very limited. This lack of satisfaction for wheelchair tennis play clothing is due to limited range of body movement compared to able-bodied tennis players, and they also have their own special movements, such as wheeling their chairs. Due to these differences in movement, the improved comfort in garment made for able-bodied tennis players would not apply for wheelchair users, and this garment can also become a source of discomfort to wheelchair users during the activity. Therefore, to effectively design functional athletic sportswear for wheelchair tennis players, the movements for wheelchair tennis players must be analyzed during play.

For ease of movement during exercise, garment comfort is a crucial factor in designing of functional athletic sportswear. ${ }^{5}$ The factor that influences garment comfort is the amount of garment strain. Garment strain is strongly associated with the space between the body and the garment during body movement. This means that lower garment strain leads to greater overall comfort. ${ }^{6}$ When this concept is applied to functional sportswear for wheelchair tennis players, the garments must be designed for the best ease of movement in a wheelchair, without undue related strain caused by the wearer's clothing. To objectively assess garment fit, CAD program was used to create $3 \mathrm{D}$ body images. Few researchers have investigated the effectiveness of garment fit using a 3D avatar with body movements. ${ }^{7}$ Using this technology, 3D avatars of the unique body movements of wheelchair tennis players can be created. These 3D avatars can then be used to objectively assess the fit of functional sportswear garments for wheelchair tennis players and patterns for these garments can then be developed. Since this study was focused on the tennis players with wheelchair users, the shirt pattern was only considered for the clothing pattern.

Therefore, the purpose of this study was to develop the shirt pattern for wheelchair tennis players to improve comfort by reducing garment strain through the use of $3 \mathrm{D}$ avatar in a CAD program.

\section{Overview of the three stages for generating design concept}

The engineering design process was utilized in order to generate the design concept of this study. The engineering design process is a problem-solving process, composed of learning, exploring, analyzing, 
and implementing. ${ }^{8}$ Since engineering design is the application of scientific knowledge to solve the technical problems of function based design, ${ }^{9}$ the engineering design method can be a powerful tool to demonstrate a useful perspective in functional clothing design. This study applied the engineering design process that has three stages:

\section{i. Understand the opportunity \\ ii. Develop the design concept \\ iii. Implement that concept. ${ }^{8}$}

During the first stage of this study, where understanding of the opportunity takes place, the wheelchair tennis players' needs in garment comfort was identified. Since garment comfort and body movements of the participants during the particular sport activity. ${ }^{10}$ Thus, in order to understand wheelchair tennis players' movements during play for the pattern design concept, body movement analysis was performed in this first stage.

Development of design concept in the second stage of this study means creation of pattern making design. For that, the clothing system for function based design needs to be determined because the clothing system is the necessary components to systematically construct the pattern. In this study, the pattern making design concept was generated by applying a morphological analysis. The morphological analysis is used to visualize new connections and features in a product and to promote creative ideas. ${ }^{8}$ In addition, morphological analysis is "an effective technique for conceptual generation of products, process and systems". ${ }^{8}$ In this regard, morphological analysis was utilized to offer potential pattern solutions of the tennis shirt pattern design problems.

For the third stage, which is the implementation of the pattern design concept, the potential tennis shirt pattern designed in the previous stages were developed and evaluated on the 3D avatars. To develop the tennis shirt pattern, a 2D block pattern was first constructed using the CAD program based on each possible solution offered in morphological matrix $\left(\right.$ OptiTex $\left.^{\mathrm{TM}}\right)$. Using 3D simulation, the block patterns were then draped onto the $3 \mathrm{D}$ avatar. Effective solutions were then determined among the possible pattern solutions for each type of movement based on the 3D avatar draping. In addition, through 3D draping, each effective pattern was further developed by focusing on any impediment of the strain on the virtual garment during body movements. Then, the virtual prototype was evaluated through "Tension map", provided by OptiTexSuit" ${ }^{\mathrm{TM}}$. A tension map represents the range of colors as the scope of the values, which means that the values show tension, or the stretch found in the garment. ${ }^{11}$

\section{Body movement analysis and creating the 3D avatars in the first stage}

For the present study, Jin and Mullet's ${ }^{12}$ pre-study was used for the analysis of body movements for wheelchair tennis players. In the prestudy, seven body movements were analyzed through the observation of arm and trunk movement along with the detection of garment strain using the Watkin's method. ${ }^{13}$

Also, this study created $3 \mathrm{D}$ body images, also called the 3D avatar, using a 3D body scanner. In order to create the 3D avatars with movements, a 3D body scanner was used to scan the individual body movements based on the analyzed seven body movements of wheelchair tennis player. The 3D body scanner, produced by "Size Stream", was used to scan the body postures. A subject who could play wheelchair-tennis was recruited and the necessary body measurements were taken. The scanned seven body movements were transferred into the Optitex software program to produce 3D avatars. The translated body scan data produced some unexpected holes on the 3D body surface. Holes are areas where the scan could not be completed and the area is left blank. In order to achieve accurate 3D draping on the body, these surfaces needed to be reconstructed to fill the holes. Since the holes needed to be filled, the free trial version of Mesh lab was used to reconstruct the surfaces. Table 1 showed that the analyzed body movements and their related garment strain were represented, and each creative 3D avatar was categorized.

Table I 3D avatars based on analyzed body movements and related to garment strain

\begin{tabular}{lllll}
\hline & I. Forehand & 2. Backhand & & \\
& Forehand low ball: & Forehand swing: & Backhand swing: & Backhand extension: \\
\hline & & & & \\
$\begin{array}{l}\text { The analyzed } \\
\text { body } \\
\text { movements }\end{array}$ & $\begin{array}{l}\text { To make contact with the } \\
\text { ball, racket is pulled back } \\
\text { and swung }\end{array}$ & $\begin{array}{l}\text { The dominant shoulder is } \\
\text { rotated away from the net }\end{array}$ & $\begin{array}{l}\text { Racket goes back to reach } \\
\text { the ball toward non- }\end{array}$ & $\begin{array}{l}\text { The elbow is extended } \\
\text { tominant arm follow through high in } \\
\text { the air }\end{array}$
\end{tabular}

3D avatars
based on
analyzed body
movements

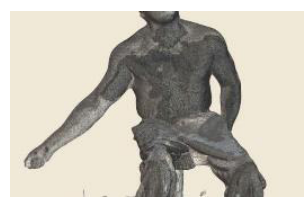

Garment strain related to body movements
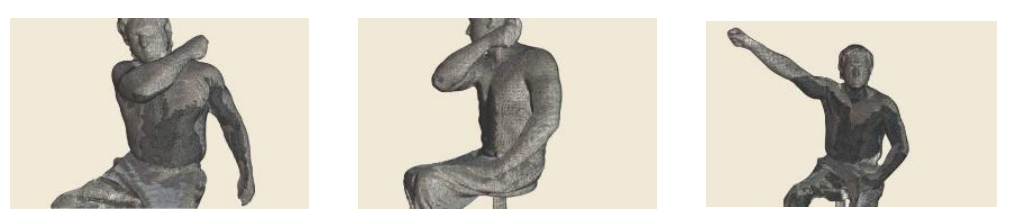

The sleeve (arm) with horizontal wrinkles, the diagonal wrinkles of the front trunk and scapular
The sleeve with horizontal wrinkles and back trunk with horizontal wrinkles
The vertical wrinkles on the shoulder and the front trunk with diagonal wrinkles 


\begin{tabular}{lll}
\hline 3. Serve & 4. Push Chair \\
\hline Serve toss: & Serve follow: & Propulsion wheelchair: \\
\hline
\end{tabular}

$\begin{array}{ll}\text { The analyzed } & \text { Toss the ball, the racket } \\ \text { moves up toward back } \\ \text { movements } & \begin{array}{l}\text { fence depending on } \\ \text { shoulder level }\end{array}\end{array}$

3D avatars
based on
analyzed body
movements

Garment strain related to body movements

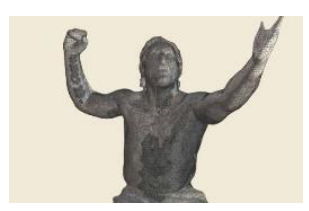

The vertical wrinkles on the shoulder, the front trunk and sleeve with diagonal wrinkles
Contact the ball with full extension, the arm follows down around the opposite side of body
Move towards ball and hand is placed on the push rim. Hands and elbows forward and down with trunk flexion toward
The development of pattern making by Morphological analysis in the second stage

In order to develop the possible pattern designs, the clothing system needed to be determined. To meet the requirements of creative design and the application of the function based design for this study, a morphological analysis was used. To develop a product design, a morphological chart offers potential solutions for each function. Function is the parameters that influence the construction of a physical device, ${ }^{8}$ which is pattern design in this study. A morphological chart addresses each function and selects possible solutions. Solutions are to solve design problems to improve physical device. In this study, morphological analysis was applied to represent potential solutions for each function of the tennis shirt garment system, and these steps are:

a. Step 1: Analyze each function of the tennis shirt pattern

b. Step 2: Based on review of literature, produce potential solutions per each function

c. Step 3: List each function in the matrix rows and record potential solutions in the matrix columns.

\section{Step I:Analysis of functions of a tennis shirt}

The function of each bodice pattern was analyzed to create functional tennis shirt pattern design. Also, to explore possible pattern-making solutions for the development of a tennis shirt pattern for comfort, the concept of Watkins ${ }^{13}$ was used. Watkins ${ }^{13}$ stated that the relationship between the shoulder angle, the bust, and the armhole is crucial in the dynamic posture. Based on this statement, the bust size, the shoulder angle as the measure of shoulder height, and the armhole as the shape at the armscye are chosen as necessary functions to construct a bodice pattern and to establish pattern drafting. Thus, the analyzed functions of a tennis shirt are shown below:

i. Bodice bust is important to determine the bodice pattern when skin is stretched or extended. Using dartless stretchy knit, tolerance of the bust area is considered since the clothing needs to accommodate both expansion and contraction for body movement. ii. Bodice shoulder angle is the horizontal section determined by taking the angle of the shoulder point and neck point. Since the shoulder angle significantly affects garment fit and comfort, shoulder elevation also needs to be considered.

iii. Bodice armhole is the depth and armscye needed to accommodate the range of movement of the arm. The shape of an armscye intersecting the bodice needs to be determined, and the depth of the armhole must correlate with the bust area on the bodice pattern.

iv. Sleeve crown determines 'the shape of an arm hanging in a relaxed position'.$^{13}$ The shape of the crown affects the arm movement. To move the arm freely, the depth of the crown and the width of the sleeve need to be considered for the shirt pattern.

\section{Step 2: Potential solutions' applying}

The methods used to make possible solutions for pattern making are the surface zone methods, wearing ease development, and adjustment lines development that include horizontal, vertical, and arc lines. Analysis of literature review of pattern development was used as necessary foundational information to guide the methods for production of potential solutions for each function. According to Yunchu and Weiyuan, ${ }^{14}$ the body surface is subdivided into surface zones by the corresponding feature lines and points based on 2D pattern cutting. Kim and Park ${ }^{15}$ also suggested that the quadrilateral grid structure method was used to create each zone. In order to use the surface zones in this study that correspond to each function of shirt pattern defined above, the upper bodice surface that relates to the geometrical zone needs to be also defined. Based on these literature reviews, ${ }^{14-16}$ the bodice bust zone, shoulder angle, and armhole zone were defined as follows:

a) Surface zone chest: The geometrical zone with a line from neck front point perpendicular to a horizontal point at the armhole to bust line and with an intersection line

b) Surface zone back: The part above the extended bust line is defined as the surface zone back between the lines with the outermost point at the armhole curve, which is perpendicular to the center back and the line which crosses the point perpendicular to the center back line 
c) Surface zone shoulder: The zone above the surface chest and back which crosses the shoulder at each neck point

d) Surface zone under armhole: The zone between the surface zone under the chest and back with the vertical line
Another method used to provide possible solutions is the adjustment lines, or structural lines, for pattern development, which utilize the chest line, the across shoulder line, the armhole diagonal line of the 2D block pattern (see red dot lines in the Table 2).

Table 2 Morphological matrix with the functions and possible solutions of shirt pattern (Bold red lines and points are blue)

\section{Solutions}

Name of function

Surface zones

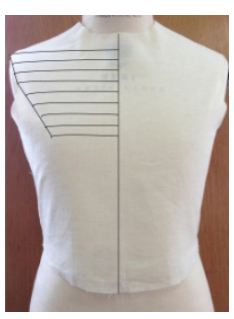

Chest Surface Zone

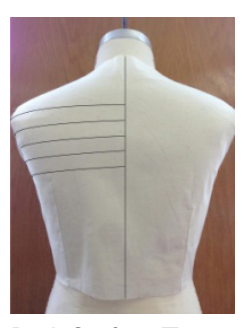

Back Surface Zone

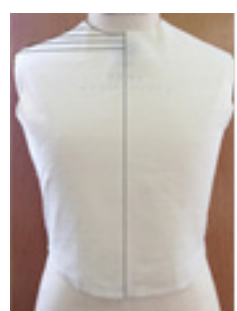

Shoulder Surface zone

Bodice armhole

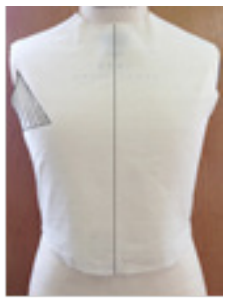

Armhole Surface Zone

Sleeve crown

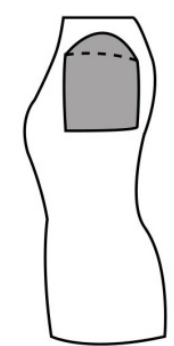

Sleeve surface zone

In addition, one of the possible solutions was presented using the wearing ease method in this study. Wang et al. ${ }^{17}$ defined that wearing ease allows wearers' movements and comfort to improve by providing sufficient space between body and garment. In this study, wearing ease was managed at the grade points of the pattern, such as the shoulder point and the under-armhole point to provide ease by changing the length (see blue dots in the Table 2).

\section{Structural lines by changing Wearing eases by changing the pieces the length of line}

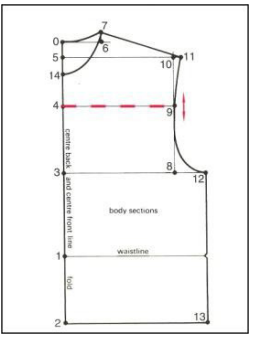

Chest structural line

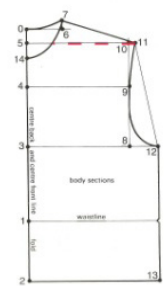

Shoulder structural line

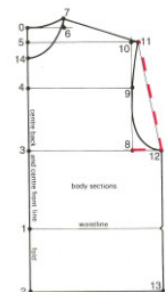

Armhole structural line

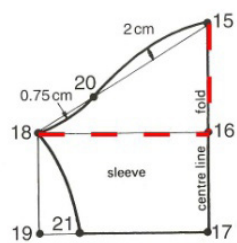

Crown width line

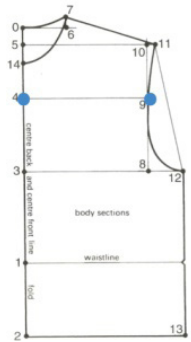

Chest width point

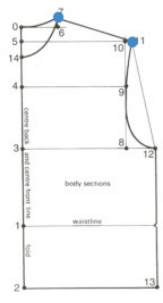

Shoulder point

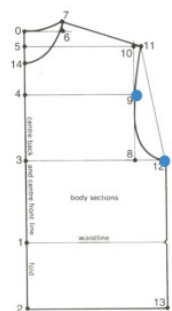

Armhole point

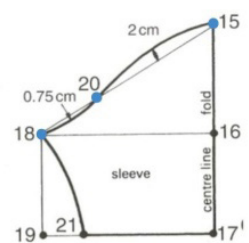

Crown point

\section{Step 3: List solutions per each function}

To create pattern design concept variants, the columns of the table were created to group the potential solutions based on function as seen in Table 4. The given potential solutions were created to meet the garment comfort aspect for each function. For potential pattern making solutions, the possible overall solution is: 
$\mathrm{m}_{1} * \mathrm{~m}_{2} * \ldots \mathrm{m}_{\mathrm{n}}\left(\mathrm{m}_{\mathrm{n}} \text { : the possibilities of } \mathrm{n}^{\text {th }} \text { function solutions }\right)^{8}$

For this study, the pattern making solutions were made for each function of the pattern as seen in Table 2 .

\section{Implement the development of pattern by 3D virtual garment in the third stage}

For the tennis shirt pattern, a 2D basic pattern was first drafted using the Aldrich's block pattern ${ }^{18}$ on the CAD program (OptiTex $\left.{ }^{\mathrm{TM}}\right)$. These basic patterns were constructed based on the possible function's solutions provided in the morphological analysis of the second stage. Then, in the third stage, these 2D patterns were transferred and draped on $3 \mathrm{D}$ avatar using $3 \mathrm{D}$ virtual garment. Evaluation of these patterns was then performed in 3D avatar to detect if there is further need of improvement of comfort using garment strain. When there is such a need, the pattern was improvised again by revisiting second stage to refine the 2D pattern. Since this study was to develop an effective tennis shirt pattern design for movement comfort, the strain factor was considered and its influence on the virtual garment. Optitex ${ }^{\mathrm{TM}}$ provides a tension map, which is a colored map that can depict amount of tension between the cloth and the model ("3D Tension map", 2011). The tension or strain value provided from the tension map is expressed in measurement of $\mathrm{gf} / \mathrm{cm}^{2}$. Gf $/ \mathrm{cm}^{2}$ indicates the unit of pressure exerted on the fabric sample. It is the unit of measurement to show how much pressure is exerted on the surface area of the fabric. ${ }^{19}$ The range of colors corresponds to the strain, so red and blue always

Table 3 Movements and problems related to garment strain appear in every tension map. However, the represented value of these colors differs based on the different strain value. For example, if the strain value is low, then the strain represented by the red color is not very high compared to the strain represented by the same red color on a high strain value map.

\section{Examining the garment strain for each movement}

The drafted pattern was used to drape the virtual garments in the CAD program. For the 3D stitching, since jersey fabric is shown to be the preferred tennis garment design,$^{20}$ the fabric type provided from the CAD program was selected with single knit jersey. The patterns that covered the area under the abdomen needed to be cut since the research objective was to consider comfort in upper trunk movements. Also, as this research was looking at strain factor of the garment in order to improve comfort during shoulder and arm movement, the pattern needed to be constructed above the waistline. According to Veblen, ${ }^{21}$ the waist needs to be measured on the smallest part of the torso. The waist line is identified on the 3D body as being $102.12 \mathrm{~cm}$, and thus the pattern block could be cut along this waistline. In the next step, the virtual garments derived from the original pattern were draped for each movement. Also, in this step, the strain areas of the pattern design were identified using the tension map. Further development of the pattern design was accomplished through releasing garment strain for each movement based on information from the tension map. Table 3 shows the strain on the specific zone for each movement and specifies the possible pattern problems related to that strain.

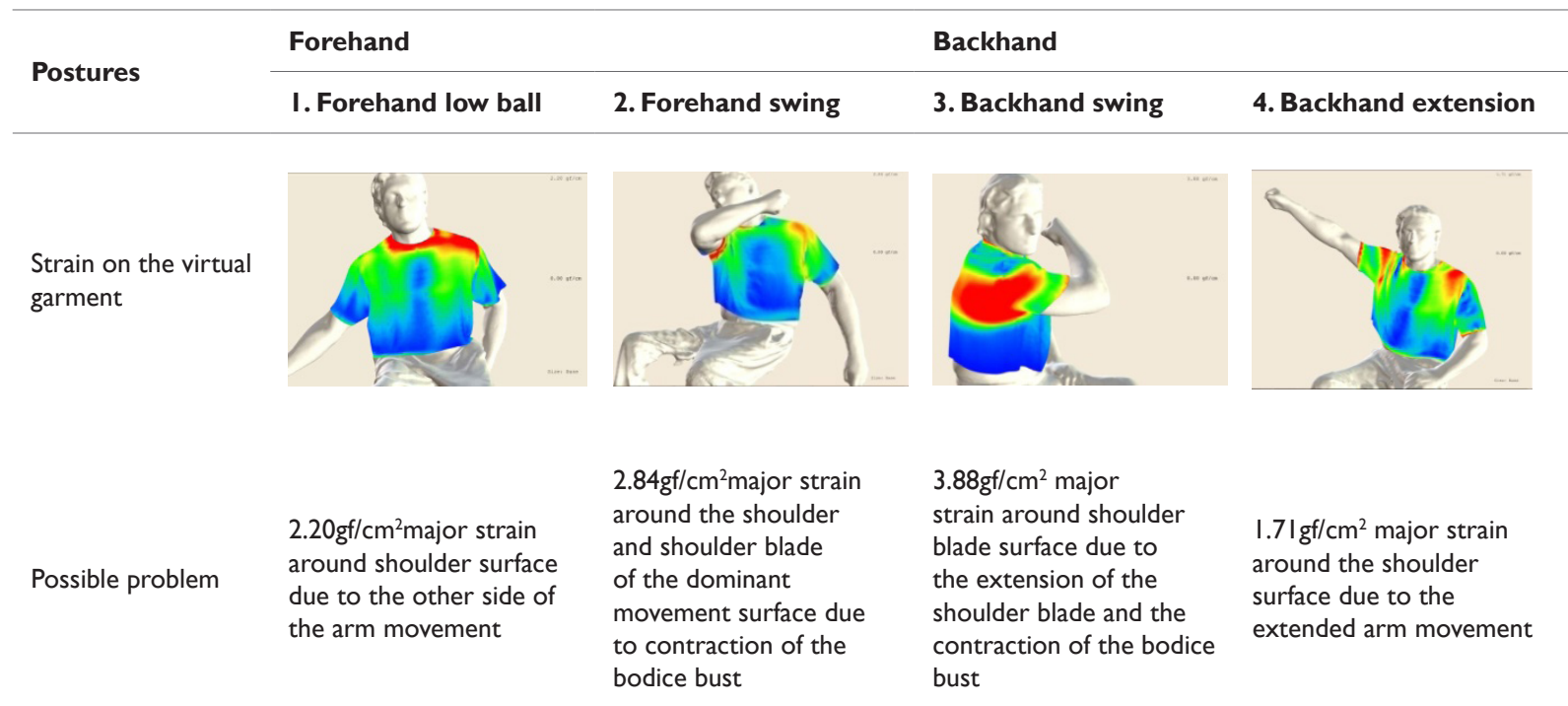

Postures

Serve

5. Serve toss

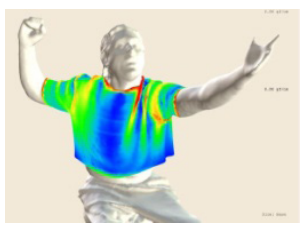

6. Serve follow

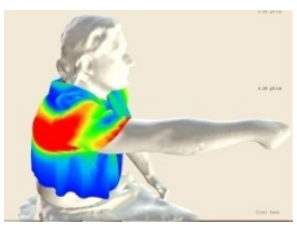

Push chair

7. Propulsion wheelchair

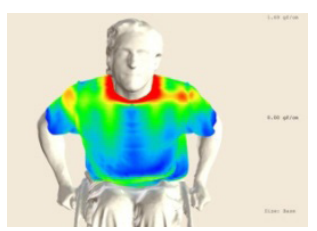


Table Continued..

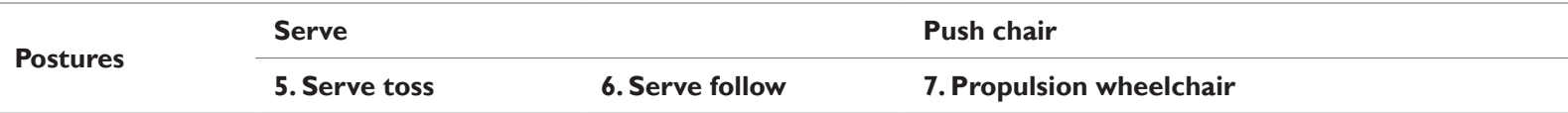

$\begin{array}{lll}\text { Possible problem } & \begin{array}{l}2.86 \mathrm{gf} / \mathrm{cm}^{2} \text { major strain } \\ \text { around the shoulder } \\ \text { around neck surface and } \\ \text { shoulder blade due to } \\ \text { shoulder movement }\end{array} & \begin{array}{l}\mathrm{cm}^{2} \text { major strain } \\ \text { sleeve due to extension } \\ \text { of the shoulder blade } \\ \text { and contraction of the } \\ \text { bust zone }\end{array}\end{array}$

\author{
$1.69 \mathrm{gf} / \mathrm{cm}^{2}$ major strain around neck surface due to the \\ trunk of the body leaning forward and the accompanying \\ shoulder movement
}

Based on the strain found on the specific surface zone of 3D virtual garment, the pattern was improvised to release these strains using either or both the structural line and/or wearing ease. In all of the movements, the majority of garment strain appeared on the shoulder surface and around the neck as the bodice shoulder angle function. The majority of other strain found was on the shoulder blade as the bodice bust function during movements in the forehand swing, backhand swing, serve toss, and serve follow through postures (Table 3 ). Based on this result, to release the tension on the specific zones of the body, the shoulder surface zone pattern was first altered, then the back surface zone altered pattern was added onto the first altered pattern to develop optimal wheelchair tennis shirt that has the least garment strain for all types of movements.

\section{The first altered pattern to reduce strain on the shoulder surface zone}

Based on the identified strain and the pattern problems, the first pattern was developed to release the tension on the shoulder surface zones (Table 4). Since the strain was located along the shoulder seam line, the shoulder structural line needed to spread in a parallel way. ${ }^{22}$ In addition, the shoulder wearing-ease point was changed to expand the shoulder length due to the major strain shown at the surrounding shoulder point. ${ }^{21}$

Table 4 Solving the problem of the bodice shoulder angle function

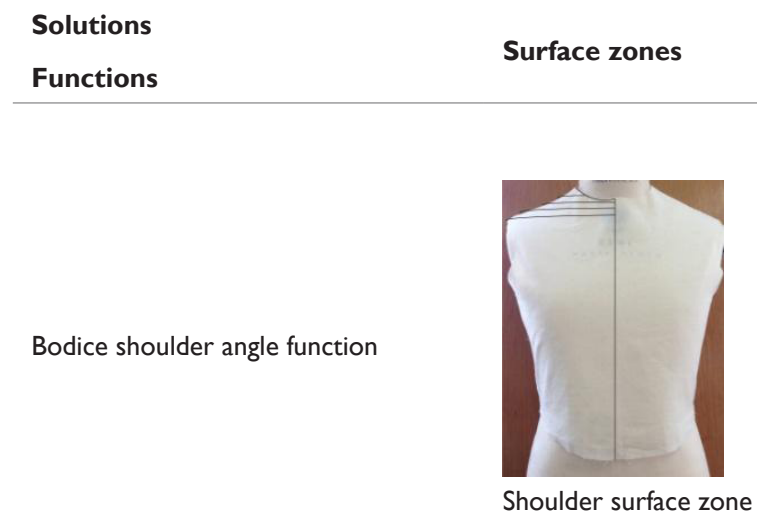

For this reason, shoulder structure line was extended $1.5 \mathrm{~cm}$ to expand the zone of the front shoulder line. Then, shoulder points were employed to increase the shoulder line by $0.5 \mathrm{~cm}$. The altered first pattern was then applied for each posture and the strain was measured again. The standard posture as the reference in the first pattern was used to measure the strain. Since the measured highest strain of the standard position was $1.57 \mathrm{gf} / \mathrm{cm}^{2}$ after modifying the patterns, the strain on the original pattern was thus reduced from $1.68 \mathrm{gf} / \mathrm{cm}^{2}$ to $1.57 \mathrm{gf} / \mathrm{cm}^{2}$. Based on these modified patterns, each movement posture was draped to measure the strain individually (Table 5).

\section{The second altered pattern to reduce strain on the bodice back surface zone}

Based on the tension map for the original reference pattern, the maximized strain was found on the back surface zone of the shoulder blade during the movements for forehand swing, backhand swing and serve follow through postures. To release this strain, the chest structural line of the back and the wearing-ease point of the back were modified (Table 6). The second pattern development was constructed based on the first pattern development to further improve comfort for the entire motion of movement during tennis play.

To improve the comfort of the shoulder blade zone, the pattern design was modified using Kernaleguen techniques, ${ }^{23}$ which states that the reference line across the shoulders on the back should change to improve comfort when using the back muscles. In addition, to release the strain across the shoulders of the upper back, the center back was changed to a curved line going to the outside with $1.5 \mathrm{~cm}$ length. Thus, based on the literature, the chest structural line of the back was spread $1 \mathrm{~cm}$ at the armhole and the chest width point of the back was moved $1.5 \mathrm{~cm}$ outside (Figure 1). 
Table 5 The different strain at each movement between the original and the first modified pattern

\begin{tabular}{llll}
\hline \multirow{2}{*}{ Postures } & \multicolumn{2}{l}{ Strain on the virtual garment } & Different strain \\
\cline { 2 - 3 } & Original pattern & The shoulder modified pattern & \\
\hline Forehand low ball & $2.20 \mathrm{~g} / \mathrm{cm}^{2}$ & $1.80 / \mathrm{cm}^{2}$ & $0.4 \mathrm{~g} / \mathrm{cm}^{2}$ \\
Forehand swing & 2.84 & 2.3 & 0.54 \\
Backhand swing & 3.88 & 3.65 & 0.23 \\
Backhand extension & 1.71 & 1.69 & 0.02 \\
Serve toss & 2.06 & 1.76 & 0.3 \\
Serve follow & 2.86 & 2.68 & 0.18 \\
Propulsion wheel chair & 1.69 & 1.58 & 0.11 \\
\hline
\end{tabular}

Table 6 Solving the problem of the bodice bust pattern function

$\begin{aligned} & \text { Solutions } \\ & \text { Functions }\end{aligned}$
Bodice bust

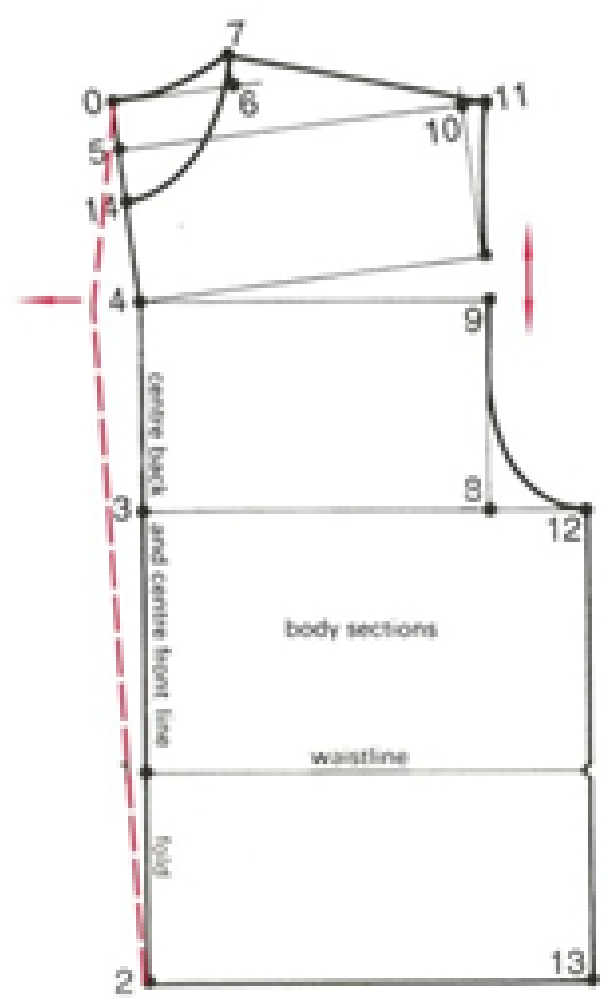

Figure I The second modified pattern for the shoulder blade back zone.

Citation: Jin HJ, Mullet K. Development of shirt pattern for wheelchair tennis players through 3D avatars.J Textile Eng Fashion Technol. 2020;6(2):50-59. DOI: 10.15406/jteft.2020.06.00230 
In order to drape the second pattern, the back bodice now had a new stitching line in the center of the back. The developed second pattern was first draped on the standard posture. In this posture, the strain value has only increased slightly at 0.02 rather than a release.
It seems that the seam line of the center back might indeed affect the strain of the bodice bust zone on the garment. In the Table 7, all the different measured strain on the garments with the shoulder blade modified patterns were shown for each movement.

Table 7 The garment strain for the shoulder blade modified pattern

\begin{tabular}{|c|c|c|c|c|}
\hline \multirow{2}{*}{ Postures } & \multicolumn{2}{|l|}{ Forehand } & \multicolumn{2}{|l|}{ Backhand } \\
\hline & I. Forehand low ball & 2. Forehand swing & 3. Backhand swing & 4. Backhand extension \\
\hline $\begin{array}{l}\text { Strain on the } \\
\text { virtual garment }\end{array}$ & $1.75 \mathrm{gf} / \mathrm{cm}^{2}$ & $2.11 \mathrm{gf} / \mathrm{cm}^{2}$ & $2.95 \mathrm{gf} / \mathrm{cm}^{2}$ & $1.66 \mathrm{gf} / \mathrm{cm}^{2}$ \\
\hline \multirow{2}{*}{ Postures } & Serve & & \multicolumn{2}{|l|}{ Push chair } \\
\hline & 5.Serve toss & 6. Serve follow & \multicolumn{2}{|l|}{ 7. Propulsion wheelchair } \\
\hline $\begin{array}{l}\text { Strain on the } \\
\text { virtual garment }\end{array}$ & $1.66 \mathrm{gf} / \mathrm{cm}^{2}$ & $2.56 \mathrm{gf} / \mathrm{cm}^{2}$ & $1.60 \mathrm{gf} / \mathrm{cm}^{2}$ & \\
\hline
\end{tabular}

\section{Evaluation of the result}

\section{Draping for the forehand low ball movement}

In this movement, when compared to the first altered pattern, the strain distribution did not change much while the shoulder strain was reduced a little from $1.80 \mathrm{gf} / \mathrm{cm}^{2}$ to $1.75 \mathrm{gf} / \mathrm{cm}^{2}$. The difference of strain compared to the original pattern is 0.45 , whereas the difference from the first altered pattern is only 0.05 . It seems that the strain around the shoulder blade was not affected much by the change made in second pattern for this forehand movement because the second pattern only modified the back shoulder blade, which has little effect on this forehand movement (Table 8).

Table 8 Overall the changed garment strain on each movement

\begin{tabular}{|c|c|c|c|c|c|c|}
\hline Body movement & $\begin{array}{l}\text { Original } \\
\text { pattern }\end{array}$ & Pattern I & $\begin{array}{l}\text { Change with } \\
\text { original }\end{array}$ & Pattern 2 & $\begin{array}{l}\text { Change with } \\
\text { original }\end{array}$ & $\begin{array}{l}\text { Change with } \\
\text { pattern I }\end{array}$ \\
\hline $\begin{array}{l}\text { Reference: } \\
\text { Standard posture }\end{array}$ & 1.68 & 1.57 & $\begin{array}{l}-0.11 \\
(\downarrow 6.5 \%)\end{array}$ & 1.59 & $\begin{array}{l}-0.09 \\
(\downarrow 5.3 \%)\end{array}$ & $\begin{array}{l}0.02 \\
(\uparrow I .3 \%)\end{array}$ \\
\hline Forehand low ball & 2.2 & 1.8 & $\begin{array}{l}-0.4 \\
(\downarrow \mid 8.2 \%)\end{array}$ & 1.75 & $\begin{array}{l}-0.45 \\
(\downarrow 20.5 \%)\end{array}$ & $\begin{array}{l}-0.05 \\
(\downarrow 2.8 \%)\end{array}$ \\
\hline Forehand swing & 2.84 & 2.3 & $\begin{array}{l}-0.54 \\
(\downarrow 19.0 \%)\end{array}$ & 2.11 & $\begin{array}{l}-0.73 \\
(\downarrow 25.7 \%)\end{array}$ & $\begin{array}{l}-0.19 \\
(\downarrow 8.3 \%)\end{array}$ \\
\hline Backhand swing & 3.88 & 3.65 & $\begin{array}{l}-0.23 \\
(\downarrow 5.9 \%)\end{array}$ & 2.95 & $\begin{array}{l}-0.93 \\
(\downarrow 23.9 \%)\end{array}$ & $\begin{array}{l}-0.7 \\
(\downarrow \mid 9.2 \%)\end{array}$ \\
\hline Backhand extension & I.7I & 1.69 & $\begin{array}{l}-0.02 \\
(\downarrow 1.2 \%)\end{array}$ & 1.66 & $\begin{array}{l}-0.05 \\
(\downarrow 2.9 \%)\end{array}$ & $\begin{array}{l}-0.03 \\
(\downarrow 1.7 \%)\end{array}$ \\
\hline Serve toss & 2.06 & 1.76 & $\begin{array}{l}-0.3 \\
(\downarrow \mid 4.6 \%)\end{array}$ & 1.66 & $\begin{array}{l}-0.4 \\
(\downarrow 19.4 \%)\end{array}$ & $\begin{array}{l}-0.1 \\
(\downarrow 5.7 \%)\end{array}$ \\
\hline Serve follow through & 2.86 & 2.68 & $\begin{array}{l}-0.18 \\
(\downarrow 6.2 \%)\end{array}$ & 2.56 & $\begin{array}{l}-0.3 \\
(\downarrow 10.5 \%)\end{array}$ & $\begin{array}{l}-0.12 \\
(\downarrow 4.5 \%)\end{array}$ \\
\hline Propulsion wheelchair & 1.69 & 1.58 & $\begin{array}{l}-0.11 \\
(\downarrow 6.5 \%)\end{array}$ & 1.6 & $\begin{array}{l}-0.09 \\
(\downarrow 5.3 \%)\end{array}$ & $\begin{array}{l}0.02 \\
(\uparrow । .3 \%)\end{array}$ \\
\hline
\end{tabular}

\section{Draping for the forehand swing movement}

In the identification of pattern problem steps, it was determined that the shoulder blade zone has major strain during the forehand swing posture. This is why the second altered pattern was developed to especially improve the comfort of the shoulder blade. In this forehand swing movement, the draped garment strain value decreased to $2.11 \mathrm{gf} / \mathrm{cm}^{2}$, and the comfort of the shoulder blade zone increased since the strain to the shoulder blade was released (Table 8). Instead of major strain on the moving dominant shoulder blade, the major strain now appeared on the other shoulder.

\section{Draping for the backhand swing movement}

The major strain of the backhand swing movement also decreased for the second pattern to $2.95 \mathrm{gf} / \mathrm{cm}^{2}$. The strain for second pattern 
decreased from the original pattern to 0.93 while the released comfort from the first pattern was 0.7 . This means that the strain values for this movement was distinguished to be larger range values than for other movements. This finding indicates that Backhand swing posture has the most influence on the shoulder blade movement. The strain on the shoulder blade improved noticeably with the second pattern when compared to the first pattern.

\section{Draping for the backhand extension movement}

In the Backhand extension movement, the strain value indicated to be $1.66 \mathrm{gf} / \mathrm{cm}^{2}$. In this movement, the strain on the second pattern slightly decreased from the first pattern, and the changed strain degree was 0.03 (Table 8). The reason for the small decrease in strain in the second pattern when compared to the first pattern suggests that the extended arm movement does not have much influence on the formation of strain on the shoulder blade. The major strain, then, is distributed on the sleeve due to the extension of the arm movement. Based on a comparison of the strain in the standard movement at $1.68 \mathrm{gf} / \mathrm{cm}^{2}$ and the strain on the garment in this movement at $1.66 \mathrm{gf} /$ $\mathrm{cm}^{2}$, it appears that garment strain did not affect the performance of this movement.

\section{Draping for the serve toss movement}

The second pattern was draped on the virtual garment for a serve toss movement. The strain showed as $1.66 \mathrm{gf} / \mathrm{cm}^{2}$. In this movement, the major strain appears at the neck and shoulder blade zone in the original pattern. After draping with the first pattern, that strain was reduced from 2.06 to 1.76 , and the strain on the second pattern was measured as 1.66 which indicates a reduced strain value. These results explain that the serve toss movement affects the shoulder blade, and that the second pattern is more effective in reducing that strain than the first pattern.

\section{Draping for the serve follow through movement}

In the serve follow through posture movement, the strain measured at $2.56 \mathrm{gf} / \mathrm{cm}^{2}$ when the second pattern was applied was less than the first pattern, and their change of the strain on the shoulder blade was similar. These results explain that the expansion of arm movement can be affected by garment strain on the shoulder blade zone. Since the second pattern was developed to improve the comfort around the shoulder blade, draping on the back of the 3D body was smoother than the first pattern, and the strain on the shoulder blade zone was released further when compared to the first pattern (Table 8).

\section{Draping for the propulsion wheelchair movement}

The second pattern was draped on the Propulsion wheelchair movement, and the strain value showed to be $1.60 \mathrm{gf} / \mathrm{cm}^{2}$. Tension on the clothing had the smallest value for this movement when compared to the other movements. In addition, the difference in strain value on the original pattern for this movement and the standard posture is only 0.01 . Therefore, garment strain had no significant impact on the performance of this particular movement.

\section{Discussion}

The present study used a morphological matrix to generate the design concept to solve the problems involved in pattern development. In this matrix, a basic tennis shirt pattern was deconstructed into each necessary function component to establish pattern drafting. Chen and $\mathrm{Lai}^{24}$ used the morphological analysis to seek design ideas for the western apparel in the Renaissance era. The western apparel was decoded into each style in the column of a table, and all possible design solutions were demonstrated in each design attributes on the row in the morphological matrix. The researchers asserted that this morphological matrix was suitable to increase possible design ideas than traditional design creation methods, such as brainstorming. The present study utilized such a matrix in order to find potential solutions of better comfort for each function of the pattern. Also, in this study, structural lines and wearing ease were used as methods to develop and alter patterns to find different potential solutions. Therefore, working around different functions for the ideal design can be a novel approach to create various design ideas or to solve the problems of pattern development.

This study shows the different garment strains from each movement compared to the standard position. For the pattern development, all movements that the athlete is likely to engage in need to be considered for the players' comfort. Comparatively, Mochimaru and Park ${ }^{25}$ stated that playing traditional tennis requires vigorous twisting of the upper body, whereas the present study of wheelchair tennis showed that movements of the shoulder area cause the dominant strain.

This study suggests reduction of the garment strain value to develop the pattern. Prior research has concluded that garment strain greatly affects the wearer's overall comfort. ${ }^{6}$ To evaluate the patterns for comfort during movements, Choi and Ashdown ${ }^{26}$ used subjective opinions of the participants. Also, in order to assess the prototype garment fit through 3D scans, Song and Ashdown ${ }^{27}$ used the determination of judges. However, as a 3D CAD system enables the assessment of tension between the clothing and the body, the pattern development in the 3D CAD uses strain values to increase comfort with more objectivity than other assessments. Even though the strain value provided from the CAD program needs further examination, the findings of this study, which showed the different strain values of each movement, can be utilized for research related to the improvement of comfort for specific movements. Such research may include development of athletes' sportswear to be worn while recovering from injuries. ${ }^{29}$

\section{Conclusion}

This study shows the analyzed body movements and their relation to garment strain through the 3D avatar. In addition, based on these results, patterns were developed to improve movements through the reduced garment strain. The first pattern was developed to release the strain on the shoulder surface zone for all movements when compared to the reference pattern. In this first modified pattern, the strain for forehand movements, including forehand low ball and forehand swing postures, were effectively decreased more than other movements. Another major strain on the shoulder blade area was considered in the second pattern. During draping with the second pattern for each movement, the strain relatively decreased for four movements, including forehand swing, backhand swing, serve toss, and serve follow through. When compared to the first pattern, especially for the backhand swing posture, strain was released by a large degree. For both the backhand extension and propulsion wheelchair postures, the second pattern did not improve the comfort as much by releasing strain. Based on these results, this study determined that the altered patterns that focused on bodice shoulder and back functions being effectively applied can reduce garment strain during the analyzed wheelchair tennis movements. Therefore, released strain was observed in the backhand swing posture because the improved pattern modified 
the shoulder blade area to extend farther during shoulder blade movement. Also, for wheelchair users during play, the movements affecting the shoulder blade, such as back swing posture and serve toss posture, showed to have greater reduction in strain than compared to other movements. This finding through objective evaluation using the $3 \mathrm{D}$ virtual garments implies that the altered patterns are effective methods used to reduce the strain on the bodice and shoulder zone during wheelchair tennis movements, and thus provide better comfort when performing these particular movements. For the athletic apparel industry, these findings can be used to commercialize production to improvement of the comfort of garments for wheelchair tennis players during play.

\section{Acknowledgments}

None.

\section{Funding}

None.

\section{Conflicts of interest}

Authors have declared no conflicts of interest.

\section{References}

1. Devivo MJ, Go BK, Jackson AB. Overview of the national spinal cord injury statistical center database. The Journal of Spinal Cord Medicine. 2002;25(4):335-338.

2. Roy J, Menear K, Schmid M, et al. Physiological responses of skilled players during a competitive wheelchair tennis match, Journal of Strength and Conditioning Research. 2006;20(3):665-671.

3. Goosey-Tolfrey V, Diaper N, Crosland J, et al. Fluid intake during wheelchair exercise in the heat: Effects of localized cooling garments. International Journal of Sports Physiology and Performance. 2008;3:145-156.

4. Mason BS, Porcellato L, van der Woude LH, et al. A qualitative examination of wheelchair configuration for optimal mobility performance in wheelchair sports: a pilot study. Journal of Rehabilitation Medicine. 2010;42(2):141-149.

5. McRoberts LB, Black CM, Cloud RM. Evaluation of a prototype softstructured thoracic posture support garment. Clothing and Textiles Research Journal. 2016;34(2):143-158.

6. Hong L, Dongsheng C, Qufu W, et al. A study of the relationship between clothing pressure and garment bust strain, and Young's modulus of fabric, based on a finite element model. Textile Research Journal. 2011;81(13):1307-1319.

7. Kozar T, Rudolf A, Cupar A, et al. Designing an adaptive 3D body mode suitable for people with limited body abilities. Journal of Textile Science \& Engineering, 2014;4(5).

8. Otto KN, Wood KL. Product design: techniques in reverse engineering and new product development. NJ: Prentice Hall Upper Saddle River; 2001

9. Nix AA, Sherrett B, Stone RB. A function based approach to TRIZ Proceedings of ASME International Design Engineering Technical Conferences' 2011:29-31.
10. Watkins SM. Clothing: The portable environment. 2nd ed. Ames, IA: Iowa State University Press; 1995:334-355.

11. 3D: Tension Map. 2011.

12. Jin H, Mullet K. Analysis of body movements for development of male wheelchair tennis shirt. International Textile and Apparel Association (ITAA) Annual Conference Proceedings ; 2013.

13. Watkins PA. Stretching performance. 2008.

14. Yunchu Y, Weiyuan Z. Prototype garment pattern flattening based on individual 3D virtual dummy. International Journal of Clothing Science and Technology. 2007;19(5)334-348.

15. Kim S, Park CK. Basic garment pattern generation using geometric modeling method. International Journal of Clothing Science and Technology. 2007;19(1):7-17.

16. Zhang LM, Zhao YX. The status analysis of volleyball apparel structure design. Advanced Materials Research. 2013;821:781-785.

17. Wang YJ, Mok PY, Li Y, et al. Body measurements of Chinese males in dynamic postures and application. Applied ergonomics. 2011;42(6):900912.

18. Aldrich W. Metric pattern cutting for menswear. Oxford: Blackwel Publication; 2011.

19. De Jong S, Snaith JW, Michie NA. A mechanical model for the lateral compression of woven fabrics. Textile Research Journal. 1986;56(12):759-767.

20. Chae $\mathrm{MH}$, Black C, Heitmeyer J. Pre-purchase and post-purchase satisfaction and fashion involvement of female tennis wear consumers. International Journal of Consumer Studies. 2006;30(1):25-33.

21. Veblen S. The complete photo guide to perfect fitting. MN, USA Minneapolis; 2012.

22. Armstrong HJ. Patternmaking for fashion design. 5th ed. Upper Saddle River, NJ: Prentice Hall; 2009.

23. Kernaleguen A. Clothing designs for the handicapped. Edmonton, Canada: University of Alberta; 1978

24. Chen Jocelyn H, Lai Cheng. The theory of morphological analysis applied to western apparel - a case study of Renaissance era. International Journal of Computer Science and Network Security. 2010;10(4):176-184.

25. Mochimaru M, Park SI. Advances in applied digital human modeling. In: Duffy VG, editor. 4D Anthropometry: Measurement and modeling of whole body surface deformation for sports garment design. CRC Press; 2010:207-216.

26. Choi MS, Ashdown SP. The design and testing of work clothing for female pear farmers. Clothing and Textiles Research Journal. 2002;20(4):253263.

27. Song HK, Ashdown SP. An exploratory study of the validity of visual fit assessment from three-dimensional scans. Clothing and Textiles research journal. 2010;28(4):263-278.

28. Masaaki Mochimaru SIP. Sports garment design. Advances in applied digital human modeling; 2010. 207 p. 